\begin{tabular}{|c|}
\hline $\begin{array}{c}\text { Analisis Hasil Program Rehabilitasi Klien Ketergantungan } \\
\text { Penyalahgunaan Narkoba di BNN Provinsi Kalimantan Timur }\end{array}$ \\
\hline $\begin{array}{c}\text { Hendri Eki Wahyuda1 }{ }^{1}, \text { Sumadi }^{2}, \text { Kartina Wulandari }^{3} \\
\text { hendrieki96@yahoo.com¹, kartinawulandari@ gmail.com³ }{ }^{3} \text { Universitas Widya Gama Mahakam, Indonesia, } \\
\text { sumadiyatmo@yahoo.com, PKBI Kota Samarinda, Indonesia }{ }^{1,3}\end{array}$ \\
\hline
\end{tabular}

Abstrak

\title{
Latar Belakang:
}

Narkoba adalah zat yang memiliki daya adiksi (ketagihan), daya toleran (penyesuaian), daya habitual (kebiasaan) yang sangat kuat, sehingga berpengaruh negative pada penggunanya.

\section{Tujuan :}

Penelitian ini bertujuan Mengetahui pengetahuan klien, sikap klien, tindakan klien, peran dukungan sosial klien saat dan dalam mengikuti program rehabilitasi ketergantungan penyalahgunaan Narkoba di Badana Narkotika Nasional Provinsi Kalimantan Timur.

\section{Metode Penelitian:}

Metode yang digunakan dalam penelitian ini adalah metode kualitatif dengan pendekatan fenomenologi melalui teknik wawancara (interview), oberservasi, dan dokumentasi pada enam informan yaitu klien rehabilitasi, orang tua klien, dan staff konselor Badan Narkotika Nasional Provinsi Kaliman.

Hasil :

Dari hasil penelitian melalui wawancara dapat diketahui bahwa pengetahuan klien dalam program rehabilitasi sudah sangat baik dan klien juga mampu mengingat ilmu apa saja yang didapat saat menjalani program rehabilitasi, terbukti dengan sikap klien yang mampu menjelaskan dan menerima, klien menunjukan perubahan yang ikut dirasakan keluarga,klien dapat menerapkan atau mempraktekkan hal-hal yang didapat dari program rehabilitasi,dukungan yang diberikan oleh keluarga pun selalu diberikan sehingga berpengaruh terhadap kesembuhan klien agar tidak Relapse.

\section{Kesimpulan:}

Pengetahuan klien sudah sangatlah baik dan klien juga mampu menjelaskan/mengingat ilmu apa saja yang didapat saat menjalani program rehabilitasi, klien dapat merubah sikapnya dari kepribadian yang buruk dan penuh emosi dan juga menerima setiap arahan yang diberikan dan mampu menjalani setiap langkah-langkah yang ada pada saat mengikuti program rehabilitasi, dan klien pun mampu berinteraksi dengan baik kepada sesama klien maupun terhadap konselor dan mampu terbuka untuk menceritakan masalah pada klien saat mengikuti program rehabilitasi, klien menunjukan perubahan yang signifikan terhadap dirinya, dukungan yang diberikan orang tua maupun konselor sangatlah berpengaruh terhadap penyembuhan klien.

Kata kunci: Rehabilitasi, Pengetahuan, Sikap, Tindakan, Dukungan Sosial.

\section{Abstract}

Background:

Drugs are substances that have addictive power (addiction), tolerance (adjustment), habitual power (habits) that are very strong so that it hurts its users.

Objectives:

This study aims to determine the client's knowledge, client attitudes, client actions, the role of client social support when and in participating in drug abuse dependency rehabilitation programs in the National Narcotics Narcotics Board of East Kalimantan.

\section{Research Metodes:}

The method used in this research is a qualitative method with a phenomenological approach through the interview, observation, and documentation techniques for six informants, namely rehabilitation clients, client's parents, and counselling staff of the Kaliman Province National Narcotics Agency.

Results:

From the research results through interviews it can be seen that the client's knowledge in the rehabilitation program is very good and the client is also able to remember any knowledge gained while undergoing the rehabilitation program, as evidenced by the attitude of the client who can explain and accept, the client shows the changes that are felt by the family, the client can apply or practice the things that are gained from the 
rehabilitation program, the support given by the family is always given so that it affects the healing of the client so that he does not relapse.

Conclusion:

The client's knowledge is very good and the client is also able to explain/remember any knowledge gained while undergoing a rehabilitation program, the client can change his attitude from a bad personality and full of emotion and also accept every direction given and be able to go through each of the steps in when participating in a rehabilitation program, and the client can interact well with his fellow clients and counsellors and can be open to sharing problems with clients while attending the rehabilitation program, the client shows significant changes to himself, the support is given by parents and counsellors is very influential in healing client.

Keywords: Rehabilitation, Knowledge, Attitudes, Actions, Social Support.

DOI $\quad$ : http://dx.doi.org/10.24903/kujkm.v5i1.836

\begin{tabular}{|l|l|l|}
\hline Received & $:$ & September 2019 \\
\hline Accepted & $:$ & November 2019 \\
\hline Published & $:$ & December 2019 \\
\hline
\end{tabular}

\section{Copyright Notice

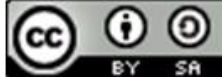

This work is licensed under Creative Commons Attribution 4.0 International License.

P-ISSN: 2477-1880 E-ISSN: 2502-6623

\section{PENDAHULUAN}

Laporan tahunan United Nations Office on Drugs and Crime(UNODC2017). Menyebutkan diperkirakan narkoba seperempat miliar orang, atau sekitar $5 \%$ dari populasi orang dewasa yang berusia 15-64 tahun, menggunakan obat setidaknya sekali pada tahun 2015 (kisaran: 158 juta hingga 351 juta), Secara global, lebih dari $11 \%$ orang yang menggunakan narkoba, atau sekitar 29,5 juta orang (rentang: 15,3 juta hingga 43,1juta), diperkirakan menderita karena ketergantungan penyalahgunaan Narkoba.

Narkotika dan obat terlarang serta zat adiktif/psikotropika dapa menyebabkan efek dan dampak negaif bagi pemakainya. Dampak negatif tersebut tentunya merugika dan memilikiefek yang sangat buruk bagi kesehatan mental dan fisik seorang hingga menyebabkan kematian bagi si pengguna hal ini dibuktikan pada tahun 2015 terdapat 50 orang yang meninggal setiap harinya dan sebanyak 18.250 orang yang meniggal akibat narkoba petahunnya (BNN,2016). Menanggapi hal tersebut maka dilakukanlah upaya pencegahan salah satunya yaitu dengan menjalakan adanya program rehabilitasi dan pasca rehabilitasi yang diperuntukan untuk memulihkan masyarakat yang terjebak dalam narkoba.

Di Indonesia sendiri Berdasarkan data penelitian dari Badan Narkotika Nasional Republik Indonesia yang bekerjasama dengan Pusat Penelitian Kesehatan Universitas Indonesia yang bekerjasama dengan pusat penelitian Kesehatan Universitas Indonesia Bahwa 
angka prevalensi penyalahguna Narkoba di indonesia telah mencapai $4,74 \%$ tingkat penggunanya atau 4.098.029 juta orang (BNN,2017). Jumlah penyalahguna tersebut tentunya telah meningkat dari tahun sebelumnya yaitu pada tahun 2016 yang berjumlah 3.416 .995 juta orang penyalahguna (KOMINFO, 2016).

Untuk daerah Provinsi Kalimantan Timur Sendiri Menduduki peringkat ke 3 di Indonesia dengan jumlah penyalahguna terdapat 63.873 dari 1.978 .100 penduduk dikalimantan timur tahun 2015 (BNN,PUSLITKES,2015). Dari hasil rekap data kasus tersangka pengguna narkoba di Wilayah Samarinda sendiri menduduki peringkat pertama jumlah pengguna narkotika dan obat terlarang dengan persentase $60 \%$, disusul Balikpapan 20\%, kemudian sisanya daerah-daerah lain di provinsi Kalimantan Timur. Pada tahun 2015 yaitu 2.141 tersangka dan di tahun 2016 terdapat 4.293 tersangka, dan ditahun 2017 yaitu 2.783 tersangka dan di tahun 2018 terdapat 2.750 tersangka dan di tahun 2019 hingga bulan maret terdapat 776 tersangka(BNN RI, 2018).

\section{Rehabilitasi 100.000 korban} penyalahguna narkoba tahun $2015 \mathrm{BNN}$ mencanangkan upaya Rehabilitasi sebagai strategi untuk menurunkan demand narkoba dikalangan masyarakat. Kebijakan BNN mengedepankan rehabilitasi adalah untuk mengurangi jumlah pemakaian narkoba dengan pertimbangan logis apabila pecandu dirawat maka secara otomatis berhenti menggunakan narkoba. Terget yang ingin dicapai merehabilitasi 100.000 pecandu diseluruh Indonesia. Diharapkan para pecandu bisa di rehabilitasi di sentra pelayanan baik yang dimiliki BNN maupun yang dikelola oleh Kementrian Kesehatan, Kementrian Sosial atau juga partisipasi dari pihak swasta (Dahlan dalam Kompasiana, 2015).

Dan tercatat pada tahun 2017 bahwa terdapat 184 orang penyalahguna telah menjalankan program rehabilitasi sedangkan pada tahun 2018 terdapat 149 orang penyalahguna yang telah menjalankan program rehabilitasi dan pada tahun 2018 terdapat 320 orang dan pada tahun 2019 hingga bulan Juli BNN Provinsi Kalimantan Timur Telah menangani 184 orang didalam kasus penyalahguna Narkoba yang ada di Samarinda yang menjalankan program rehabilitasi di $\mathrm{BNN}$ Provinsi Kalimantan Timur.

\section{METODE PENELITIAN}

Penelitian ini menggunakan metode penelitian kualitatif dengan pendekatan Fenomenologi. Penelitian kualitatif adalah suatu pendekatan yang mengekplorasi, menemukan, menjelaskan dan menerangkan fenomena atau objek sosial yang tidak dapat dijelaskan, didefinisikan, diukur dan tidak dapat dijumlahkan secara 
numeric atau angka-angka (Afiyanti \& Rachmawati, 2014).

Didalam pendekatan fenomenologi yaitu menekankan subjektifitas pengalaman manusia, dalam pendekatan ini peneliti berusaha untuk memahami arti dari sebuah peristiwa juga kaitannya pada orang -orang dengan situasi tertentu. Dengan pendekatan fenomenologi membantu peneliti untuk masuk kedalam subyek secara konseptual sehingga peneliti mengetahui apa dan bagaimana suatu pengertian yang dikembangkan oleh subyek pada peristiwa dalam kehidupan sehari -hari nya.

\section{HASIL PENELITIAN}

1. Hasil penelitian untuk mengetahui Pengetahuan klien setelah menjalani program rehabilitasi

Berdasarkan hasil wawancara yang dilakukan dan disesuaikan dengan domain penelitian sejauh mana pengetahuan setelah menjalani program rehabilitasi :

a) Tahu

Kutipan wawancara:

Kutipan 1

"hmm,yak kalo menurut saya intinya program rehabilitasi itu ya hmm program untuk saya sendiri pulih dari ketergantungan Narkoba terus penguat untuk saya kebetulan ya sebagai mantan pengguna untuk kembali ke dunia luar lagi jadi di balai itu sebagai simulasi buat kita kembali lagi mengenal dunia luar, bagaimana kita menghadapi kaya mengenal dunia gelap tentang peredaran narkoba, karna saya juga sendiri sebelum direhab sampai saya akhirnya sadar dan pengen rasanya sembuh dari kecanduan karna saya bingung mau ngadu kemana lagi minta di sembuhkan ya meminta pertolongan selain di balai tanah merah lah jadi setelah selesai dari balai banyak memang yang aku tau,gimana cara ngontrol emosiku gimana cara kalo aku dapat masalah apa yang harus aku lakuin karna dulunya kan aku gak pernah yang namanya berbagi cerita sama siapapun, setelai keluar dari balai aku sudah tau saat aku mendapat masalah apa yang aku lakukan,apa yang harus aku ceritakan keluh kesahku. Ya banyak sih ya yang aku dapatkan dari program rehabilitasi mulai dari pengelolaan pola pikir juga yang maunya harus instan yang aku mau diluapkan dengan itu makai narkoba, kalo sekarang Allhamdulilah aku ceritakan ke orangtuaku"

(W.A.MA.3)

informan utama lainnya :

Kutipan 2

"ya apa yang aku dapatkan ya aku terapkan ke luar juga kan contohnya ya kaya tadi cara berbica dengan baik ke orang orang terus gimana caranya aku ngontrol emosi aku biar ga lari ke narkoba lagi.biar bisa kumpul dengan keluarga ke sirkle ya lebih positif lagi" (W.A.HS.7)

informan kunci menjelaskan tentang pengetahuan berikut:

Kutipan 3 
"okeee jadi program rehabilitasi itu kan sebenarnya program yang diperuntukan bagi korban penyalahgunaan narkoba, dimana maksudnya mereka ini yang membutuhkan tempat petolongan agar dapat pulih dari penyalahgunaan narkoba dek,nah kita berbicara rehabnya itu sendiri,dek program dari pusat yang berkelanjutan jadi pada saat penerimaan awal si klien melaporkan diri agar dapat direhab dan menjalankan setiap peraturan dan kegiatan yang diterapkan program rehabilitasi itu sendiri hingga mereka kembali kekeluarga mereka lagi dan pulih kembali seperti orang normal..." (W.B.I.1)

Kutipan 4

"ilmu yang didapat itu pastinya adalah ilmu tentang adiksi dek contohnya dia kan pernah make nih dek nah efek dari dia make narkoba untuk tubuh mereka itu nanti gimana,dan juga dia kan tau tuh kondisi tempat tempat dimana barang itu didapan atau dimana mereka biasa make bersama temannya sesama pengguna jadi setelah dia keluar dari program rehab dia bisa membentengi diri dia agar dapat mengendalikan rasa ingin make itu gimana, apayang harus mereka lakukan ketika rasa ingin make itu tumbul lagi contohnya lebih cerita kepada keluarga terbuka gitu dianya terus dibawa ke aktifitas aktifitas positif supaya rasa itu bisa mereka atasi.." (W.B.I.6)

b) Memahami

Dari hasil wawancara informan menjelaskan materi yang diberikan selama menjalani program rehabilitasi, diketahui informan memahami isi dari pemberian materi selama menjalani program rehabilitasi. Hal ini sesuai dengan kutipan wawancara berikut ini :

Kutipan 5

"contohnya anger management itu kaya pengelolaan rasa marah kita misalkan aku marah nah disana aku diajarkan gimana cara aku ngrontol rasa marahku tu gimana terus cara mengeluarkannya tu gimana. Terus ada juga naamanya tu comunication effectiv, comunication effectiv tu kita diajarkan gimana cara kita berbicara dengan orang orang sekitar dengan baik tu gimana karna kalo dulu kan saya sebelum ikut rehab aku ga bisa ngontrol cara aku ngomong ke orang kan gimana ya kan"

(W.A.MA.10)

informan utama lainnya :

Kutipan 6

"iya,materinya banyak bro hmm contohnya kaya tadi bahaya narkoba itu tadi hmm terus materi buat ngelola emosi biar gimana caranya meluapkan emosi engga langsung lari ke narkoba jadi biar ke hal hal yang positif lah bro terus juga cara berkomunikasi dengan orang orang itu gimana yang baik bro" (W.A.HS.6)

informan kunci. Sebagai Berikut :

Kutipan 7

"kalo untuk materi itu jelas dek karna materi itu sendiri adalah program utama dari program rehabilitasi itu sendiri,contohnya seperti materi motivasi diri agar klien bisa merubah pola pikir mereka sehingga proses pemulihan mereka bisa mereka jalanin 
dengan mudah,ada juga materi relapse prevantion, terus juga materi kejatuhan dimana merubah stigma klien saat dia keluar dari rehabilitasi bisa mengadapi stigma masyarakat dan membuktikannya bahwa dia bisa pulih ya lebih mengembalikan keperayaan bahwa klien ini bisa sembuh gitu dek..."

\section{(W.B.I.5)}

Hal ini dapat disimpulkan bahwa pemberian materi selalu diberikan kepada klien saat menjalani program rehabilitasi dan klien juga mampu memahami isi selama materi diberikah oleh pihak BNN Provinsi Kalimantan Timur, hal itu juga sesuai dengan apa yang dinyatakan oleh informan kunci tentang materi yang selalu diberikan kepada klien selama menjalani program rehabilitasi penyalahgunaan ketergantungan Narkoba di BNN Provinsi Kalimantan Timur.

2. Hasil Penelitian untuk mengetahui Sikap Klien setelah menjalani program Rehabilitasi

Berdasarkan hasil wawancara yang peneliti lakukan kepada 2 informan utama dan informan kunci mengenai sikap klien saat menjalani program rehabilitasi di BNN Prov Kalimantan Timur.Hal ini sesuai dengan domain penelitian berikut:

a. Menerima

Dari hasil wawancara tentang sikap informan utama saat menjalani program rehabilitasi di BNN Prov Kalimantan Timur, menunjukan bahwa informan mengikuti setiap arahan yang ada di program rehabilitasi. hal ini sesuai dengan kutipan wawancara berikut :

Kutipan 10

"ya langkah langkahnya yang paling besar harus aku jalani karna memang diajarkan disana ya itu sih gimana cara aku ngontrol emosiku yang dulu mau sama orang tua aja saya pake emosi terus disana diajarkan namanya nahan emosiku cara aku berbicara dengan orang dengan baik itu sih yang aku tau proses awal yang emang betul betul di tekankan selama disana"

(W.MA.13)

Kutipan 11

" allhamdulillah bisa aku terima bro karna emang dasarnya apa yang udah dikasih dari sana emang untuk aku sendiri supaya aku ga terjun kedunia narkoba lagi, ya walaupun awalnya ya gitu aku ga ngerasa nyaman dengan peraturan disana"

(W.A.MA.14)

informan utama sebagai berikut :

Kutipan 12

" ya yang pertama merubah kebiasaan buruk sebelum aku direhab kaya pola tidur berubah drastis jadi lebih produktif terus juga ngejaga pola hidup sehat, jadi lebih teratur terus ngejalanin religi sesion kaya solat 5 waktu disana terus ngontrol emosi ku gimana gitu bro"'

(W.A.HS.10)

Kutipan 13

"aku terima bro walaupun awalnya ga nyaman karna itu tadi biasanya 
begadang terus bangun siang karna engga biasa lama kelamaan terbiasa karna emang maksud dari kegiatan itu untuk kebaikan aku sendiri bro.karna dasarnya aku udah lelah"

(W.A.HS.11)

informan kunci, sebagai berikut :

Kutipan 14

"yang pertama itu dek ya kembali ke diri klien dulu harus atas niat mereka sendiri atau keinginan mereka itu sendiri untuk pulih itu sebesar apa, dan mengikuti semua aturan yang ada selama klien menjalani program rehabilitasi seperti halnya bangun pagi berolahraga mengikuti segala kegiatan yang udah diterapkan diprogram rehabilitasi itu sendiri agar dapat merubah kebiasaan buruknya mereka dulu ke lebih kegiatan produktif terus mengikuti setiap pemberian materi yang diberikan oleh program rehabilitasi juga dek intinya mereka harus mengikuti semua aturan yang ada.."

(W.B.I.8)

Kutipan 15

"nah kalo itu juga kembali ke kliennya dek ada klien yang tidak mau mematuhi karena tidakmerasa nyaman dan ada juga yang mau mengikuti segala aturan yang ada yang disediakan program rehabilitasi itu sendiri tapi dek ya sejauh ini klien mampu menerima segala aturan yang ada karna begitu besarnya harapan mereka untuk pulih kembali...seperti itu"

(W.B.I.9)

hal ini dapat disimpulkan bahwa langkah-langkah yang harus dijalani informan utama dan selama mengikuti program rehabilitasi informan utama mampu mengikuti dan menerima setiap arahan yang ada deprogram rehabilitasi yang didukung oleh kutipan dari hasil wawancara oleh informan kunci.

b. Merespon

Dari hasil wawancara tentang sikap informan utama saat menjalani program rehabilitasi di BNN Prov Kalimantan Timur, menunjukan bahwa informan selalu berinteraksi dengan baik. hal ini sesuai dengan kutipan wawancara berikut :

Kutipan 16

"ya interkasi kaya curhat flashback waktu makai nyesel rasanya terus cerita perasaan mau make tu timbul lagi biar mereka sama sama ngasih solusi apa yang harus aku lakukan ya selebihnya kaya kerja sama kalo kegiatan kelompok gitu bro, sisanya cerita cerita biasa buat lucu lucuan gitu lah buat ngibur diri biar lupa saama perasaaan mau make lagi" (W.A.MA.16)

informan utama lainnya, sebagai berikut:

\section{Kutipan 17}

"ohh sering bro sama teman sesama rehab gitu kan jadi cerita gitu keluh kesah sama sama terbuka buat nyari solusi biar ngilangin rasa pengen make lagi tu terus juga lebih ke nyari kegiatan positif, kaya "eh enaknya ngapain nih ngapain nih" gitu bro" (W.A.HS.12)

informan kunci sebagai berikut : 
Kutipan 18

"ohh selalu dek karna interaksi itu sangat penting untuk klien mebiasakan diri untuk terbuka dalam mengeluarkan semua isi perasaannya dan apa yang dia rasakan sehingga kita juga dapat membantu klien apa yang harus dia lakukan ketika mereka sedang menghadapi masalah"

(W.B.I.10)

Interaksi sangat penting untuk klien selama proses pemulihan informan selama menjalani program rehabilitasi.

4. Hasil penelitian untuk mengetahui tindakan klien setelah menjalani program rehabilitasi.

a. Evaluasi

Dari hasil wawancara peneliti mengenai perubahan yang dirasakan klien setelah menjalani program rehabilitasi di BNN Provinsi Kalimantan Timur. Hal ini sesuai dari kutipan wawancara berikut :

Kutipan 19

"ya jauh lebih baik aja gitu kaya dulunya suka emosi suka ngomong kasar sama siapapun, sekarang bisa dikontrol gimana cara aku luapkan emosi dengan cara cerita masalahku dengan orang rumah, terus kalo aku pengen make aku bawa solat juga. Ya banyak lah bro susah dijelasin intinya aku lebih bisa ngontrol emosi bair aku ga kembali make lagi"

(W.A.MA.17)

Kutipan 20

"Allhamdulillah bisa aja ya rasa untuk make lagi tu ya itu tadi aku larikan kecerita sama orang rumah terus aku bawa solat juga terus juga aku mikir kalo misal aku make lagi bisa sia sia yang aku dapatkan selama disana aku juga mikir orang orang disekitarku kalo aku make lagi tu gimana gak mau ngecewain orang orang rumah kedua kalinya lah pokoknya.jangan sampai aku nyesal kalo aku make lagi orang tua ku kecewa meninggal aku nyesal itu yang aku pikir buat ngendalikan aku"

(W.A.MA.18)

Informan utama menunjukan perubahan yang dirasakan dan mampu mengendalikan diri agar tidak menggunakan Narkoba kembali. Hal ini juga didukung dari pernyataan informan utama lainnya sebagai berikut:

Kutipan 21

"seneng lah bro sekarang rasanya bisa ngejauh dari narkoba tu terus sekarang yang biasa suka emosi sendiri kalo ga make ya sekarang bisa ke lebih baik ceritakan ke orang tua bisa ngendalikan juga biar ga make lagi. Tenang juga rasanya yang biasa was was, terus bisa deket lagi sama keluarga." "

(W.A.HS.13)

Kutipan 22

" "hmm lebih ke bawa ke solat bro terus temen lama biasa make tu kadang suka ngajak aku hindari ya emang godaan gede banget ya tapi lebih aku larikan ke cerita ke orang tua karna kembali lagi ya emang cara berpikir tu berubah jadi kaya udah lah itu cuman kesenangan sesaat"

(W.A.HS.14) 
informan pendukung bahwa :

Kutipan 23

"ohhh banyak sekali yang saya rasakan perubahan yang dialami anak saya sesudah selesai dari program rehabilitasi, mulai dari pendidikan agama ya yang saya tau kan disana dibiasakan untuk menjalankan kewajibannya kan kaya solat setiap waktunya dia harus dia jagaa...yang kedua kan perhatiannya dengan orang tua mulai saya rasakan contohnya ke saya untuk mamanya ya kayak "hmm mama sudah makan kaah? Biar abi yang ambilkan makanan ya kalo mama belum makan".....terus kalo sakit "aabi bawa berobat ya maa" kaya gitu...terus juga kalo dikasih uang buat jajan sekarang bisa ngejaga uang itu buat dibelanjakan yang lebih berguna buat dia juga lebih bertangung jawab lah buat ngembalikan kepercayaan dari keluarga...betul banyak sekali terus sama teman temannya juga banyak penolakan yang dia lakukan ketika diajak main keluar rumah jugaa...dia bisa nolak buat negasin teman temannya ya walaupun temannya mengajak ke sesuatu positif ya makanya juga kadang saya kasih tau "bukan kaya gitu abi kalo teman ngajak ke yang berguna jangan main nolak gitu aja baik baik juga cara nolaknya"...ya mungkin saya ngerti ya karna dia trauma dengan ajakan teman yang dulu buat dia make lagi mungkin seperti itu yaa hmmmm..."

(W.C.M.8)

Kutipan 24

"Allhamdulillah sesudah dia pulang dari rehab itu tadi tadi yaa bisa dia kendalikan ya kembali lagi tergantung dari kita juga sebagai keluarganya untuk memberikan kepercayaan dan juga perhatian yang baik supaya anak saya selalu merasa nyaman tanpa ada tekanan dari keluarga jadi rasa make lagi tu bisa dia kendalikan karna dari kita juga sebagai keluarga selalu memberikan perhatian dengan baik gitu...ya sesekali kadang kita bawa dia jalan jalan buat hilangkan penatnya dia juga bawa dia nonton biokop ya buat dia senang lah terus kembalikan percaya dirinya dia kalau keluarga masih sayang sama dia...terus juga dia pas pulang itu langsung ngobrol sama sayaa sambil nangis "ma aku tobat maa, aku nyesal aku banyak dosa sudah sama mama sudah abi nda mau lagi kaya gitu lagi,ampunin abi ya ma" (W.C.M.9)

informan kunci, sebagai berikut :

Kutipan 25

"banyak sih dek perubahan yang ka ina alami didalam diri klien itu contohnya dari awalnya klien itu keras kepala ga bisa diatur, sampai dia akhirnya bisa melawan egonya sendiri ketika dapat masalah,mereka selalu sharing sama kami selain sama kami juga klien bercerita keluh kesahnya yang dia rasakan itu diceritakan dikeluarganya jadi selain meminta bantuan kepada kami keluarga juga bisa membantu dalam proses pemulihan klien untuk produktif kembali, dan akhirnya yang awalnya dia tidak bertanggung jawab sama keluarganya akhirnya dia bisa bertanggung jawab sama keluarganya untuk membuktikan bahwa dia ingin sembuh.. gitu dek"

(W.B.I.11) 
Kutipan 26

" kalo sejauh ini dek ya menurut pandangan kaka sendiri Allhamdulillah klien mampu mengendalikan dirinya seperti ya kaka jelasin tadi nih,yang awalnya dia tidak bertanggung jawab sama keluarganya sekarang lebih bertanggung jawab dan lebih bersemangat untuk mencarikan nafkah untuk keluarganya yang awalnya malas malasan jadi lebih produktif lagi jadi hal hal yang membuat dia ingin make tu udah bisa dia hilangkan dek"

$$
\text { (W.B.I.12) }
$$

Perubahan yang dirasakan informan utama juga ikut dirasakan oleh informan pendukung dan didukung oleh pernyataan dari informan kunci yang menyatakan bahwa informan utaman mampu mengendalikan diri agar tidak menggunakan narkoba kembali dan lebih bertanggung jawab dalam proses penyembuhannya setelah menjalani program rehabilitasi.

b. Adopsi

$$
\text { Informan utama menerapkan/ }
$$
mempraktekan yang telah diberikan dalam program rehabilitasi :

Kutipan 27

"ya pertama kaya ke solat, terus selama pembakelan gimana cara aku berbicara dengan baik, tingkah lakuku yang negatif awalnya dimata keluarga dikit demi sedikit aku rubah, emosiku juga udah aku brusaha kontrol, terus juga apa apa aku ceritakan ke orang tua"
(W.A.MA.19)

Informan menerapkan sekaligus mempraktekan yang telah diberikan dalam program rehabilitasi. Adapun dengan informan utama lainnya menyatakan bahwa :

Kutipan 28

" ya aku lebih melakukan kegiatan positif bro kaya ada pikiran mau make bawa solat, terus lebih apa apa cerita ke orang tua kekeluarga juga.ya pokoknya apa yang udah dikasih dari program rehabilitasi lah"

(W.A.HS.15)

Informan pendukung, sebagai berikut :

Kutipan 29

"ya yang itu tadi yang biasanya dia nda solat sekarang bisa jaga waktu solatnya, tidurnya juga sudah teratur kebiasaan malasnya juga sudah berubah jadi rajin...ya banyak lah pokoknya perilakunya juga udah lebih baik dari sebelum dia di rehab.."

(W.C.M.10)

Hal ini juga dinyatakan oleh hasil wawancara informan pendukung lainnya, bahwa :

Kutipan 30

" hal hal yang udah dia terapkan hm....yaa lebih sopan aja sama saya ya sekarang terus apa apa dia sekrang lebih suka cerita juga tu yang dulunya kasar dianya juga udah engga lagi.terus jugaa tuu solat dianyaa dikerjakan juga ya lebih aktif lah sekarang ini dianya...jarang keluar rumah juga tu dianyaa jadi lebih sering dirumah aja dianya dek ...sama pola 
makannya juga udah teratur sekarang"

(W.C.S.11)

Adapun hasil wawancara terhadap informan kunci terkait hal hal yang harus diterapkan informan utama setelah menjalani program rehabilitasi. Sebagai berikut :

Kutipan 31

"kalo menurut kaka sendiri nih ya dia harus jujur itu hal yang paling besar yang harus dia lakukan jujur sama diri sendiri maupun sama orang lain,karna kan dia kembali kelingkungannya nih ya kembali kekeluarganya nih rasa ingin make tu timbul nih jadi hal yang harus dia lakukan terbuka juga sehingga keluarga bisa membantu memberikan solusi yang harus dia lakukan agar tidak make lagi gitu" (W.B.I.13)

Informan menerapkan hal hal yang telah diberikan, hal itupun juga dirasakan oleh informan pendukung yang merasakan perubahan yang dialami informan utama dan sesuai yang dinyatakan oleh informan kunci tentang hal hal yang harus diterapkan informan setelah menjalani program rehabilitasi.

5. Mengetahui Peran Dukungan Sosial klien dalam menjalani program Rehabilitasi

1. Dukungan Emosional

Sesuai dari kutipan wawancara berikut :

Kutipan 32 "banyak bro karna dari kenginginan keluarga pengen aku sembuh pengen kembali seperti biasanya jadi keluraga selalu memberikan dukungan supaya aku bisa sembuh itu aja harapan dari keluarga"

(W.A.MA.23)

Kutipan 33

"ya pertama hmm nyemangatin aku, motivasi aku, nasehati aku bantu aku sama sama ngasih solusi hmm apa lagi ya"

(W.A.MA.24)

Informan utama lainnya terhadap dukungan yang diberikan dapat dilihat dari hasil wawancara sebagai berikut :

Kutipan 34

" banyak bro dari keluarga ngasih aku motivasi terus untuk aku lebih ke nasehat sih bro"

(W.A.HS.18)

Kutipan 35

"hmm nasehat itu tadi bro buat lebih perhatikan pola tidur pola makan terus kadang juga dianterin makanan cemilan,terus juga semua kebutuhan aku terpenuhi apa yang aku mau." (W.A.HS.19)

Informan

pendukung menyatakan dukungan emosional yang selalu diberikan terhadap informan utama sebagai berikut :

Kutipan 36

" ohhh hmm mendukung sekali...dia mau direhab itu semua dukungan saya kasih ya namanya anak kan yaa siapa sih orangtua yang nda sayang anaknya mau seburuk apa juga kelakuan 
anaknya tetap kasih sayang saya sebagai orang tua selalu saya berikan kepada anak saya"

(W.C.M.13)

Kutipan 37

"ya intinya dari kasih sayang saya selalu berikann kediaa...nasehat nasehat juga selalu saya kasih kedia...sama juga ketika dia ada permintaan untuk dibawakan sesuatu kaya cemilan dan itu saya sendiri yang mengantarkan kesana karna ini demi kesembuhannya dia terus juga dia merasa orang tuanya masih sayang sama dia segala permintaanya dia untuk memenuhi kebutuhan dia disana selalu saya turuti...ketika ada pertemuan khusus keluarga saya datang terus untuk mantau perkembangan anak saya tidak pernah saya tidak datang gituu.."

(W.C.M.14)

Informan pendukung lainnya juga dinyatakan dari kutipan berikut :

Kutipan 38

"ya namanya anak ya dek siapa sih orang tua yang mau buang anaknya mau anaknya ke nakal apa kurang ajar terus kelewatan juga dianya orang tuanya pasti disisi lain ngedukung buat dia berubah dek..."

(W.C.S.12)

Kutipan 39

"yaa pastinya selalu saya kasih nasehat juga dianyaa kalo saya jenguk dia sampai pulang kerumah tuuh tetep saya kasih nasehat dek...perhatian saya juga nda pernah berenti buat dia semua kebutuhan dia selama di rehab itu saya penuhi juga....dia tu kaya anak kecil soalnya waktu disana tu sering dia minta bawain cemilan cemilan ciki ciki gitu dek saya bawain maunya dia yang penting dia sembuh laah..."

(W.C.S.13)

Informan kunci menyatakan bahwa program rehabilitasi mensuuport keluarga dalam memberikan dukungan,khususnya dukungan emosional kepada klien agar dapat menyelesaikan program rehabilitai, hal ini dapat dilihat dari kutipan berikut :

Kutipan 40

"selalu dek, selalu karna program disini juga selain diperuntukan untuk klien penyalagunaan narkoba kita juga meberikan program yang namanya family support grup yang dimana kita memberika edukasi kepada keluarga bahwa dukungan keluarga itu dukungan paling utamayang harus diberikan kepada klien agar klien lebih percaya diri dalam pemulihannya dia" (W.B.I.16)

Kutipan 41

" oh iya sebenarnya ya dukungan yang paling dibutuhkan klien itu dek adalah yang pertama tidak memberikan label negatif kepada klien walaupun klien adalah seorang mantan penggunga narkoba, terus selalu diberikannya perhatian tanpa harus membedakan bedakan dia sama saudaranya dan tetap memotivasi dia sehingga dapat melancarkan proses pemulihannya dia dan tetap menyadarkan klien kalau dia tetap diberikan kepercayaan agar dapat sembuh sehingga stigma negatif didalam keluarga terhadap dirinya tidak dipikirkan sama dia gitu dek" (W.B.I.17) 


\begin{abstract}
Informan utama selalu
diberikan dukungan khususnya

dukungan emosioal oleh informan

pendukung selama menjalani program

rehabilitasi maupun setelah proses

pemulihannya, dan juga dapat dilihat

dari kutipan informan kunci yang

menyatakan program rehabilitasi

mensupport keluarga dalam

memberikan dukungan terhadap klien

saat menjalani program rehabilitasi

maupun setelah proses pemulihannya.
\end{abstract}

2. Dukungan Informasi

Informasi berupa saran dan arahan yang diberikan dalam menjalani program rehabilitasi di BNN Prov

Kalimantan Timur. Hal ini sesuai dari

kutipan wawancara berikut :

Kutipan 42

"sering sih bro kalo aku lagi suntuk aku cerita rasa pengen make tu nimbul lagi mamak nyaranin saya pasti bawa solat."

(W.A.MA.27)

Kutipan 43

"ya itu tadi bro kaya dibawa ke solat aja biar lebih ingat buat ngadu sama tuhan."

(W.A.MA.28)

Informan utama lainnya
mengenai saran dan arahan yang
diberikan dapat dilihat dari kutipan
sebagai berikut:
Kutipan 44
"iyaa selalu diingetin jangan lagi kaya
dulu terus jauhi sudah temen temen

yang dulu lebih baik bawa ke mesjid baca Qur'an ya seperti itu lah biar aku gak kembali lingkungan awal aku."

(W.A.HS.21)

Kutipan 45

"ya seperti itu lah kadang disuruh kepengajian laah nyari temen yang lebih baik dari pada temen temen yang dulu gitu. "

(W.A.HS.22)

Adapun hasil wawancara oleh informan pendukung yang menyatakan bahwa saran dan arahan selalu diberikan kepada informan utama dapat dilihat dari kutipan berikut :

Kutipan 46

"itu selalu saran sama motivasi selalu saya berikan kaya ketika dia lagi dimarahin selama disana saya nasehati "dibawa sabar aja nak jangan dilawan ya kaya kamu ngelawanin mamak semua ini kan demi kamu demi kesembuhan kamu ikutin aja ya aturan mereka" itu semua demi kenyamaan dia biar dia semangat buat disembuhkan"

(W.C.M.15)

Kutipan 47

"iyaa saya kasih arahan juga, kaya gimana menghadapi orang orang disana hadapi dengan perilaku yang baik terus juga sama orang harus sopan kalo dibentak jangan dilawan terus saya selalu berikan terus seperti itu"

(W.C.M.16)

Informan pendukung lainnya dari kutipan berikut bahwa :

Kutipan 48

" ya kaya gitu tadi dek saran yang saya kasih ke dia, nasehatin dia teruuuss 
kadang saya kasih tau sudah jangan berteman dengan yang ga baik sudah sudah cukup sampai sini aja..yaa nurut dianyaa sambil nangis dia bilang nyesel gitu dek udah dia bilang.." (W.C.S.14)

Informan kunci menyatakan bahwa :

Kutipan 49

"kalo itu pasti dek jelas karna itu juga salah satu hal yang paling dibutuhkan klien saat setelah menjalani program rehabilitasi dan kembali kekeluarganya lagi"

(W.B.I.18)

Informan utama selalu diberikan dukungan informasi berupa saran dan arahan oleh informan pendukung, dan didukung oleh pernyataan dari informan kunci dari kutipan tersebut terhadap dukungan yang diberikan selama proses pemulihan informan utama setelah menjalani program rehabilitasi.

\section{PEMBAHASAN}

1. Mengetahui pengetahuan klien setelah menjalani program

\section{Rehabilitasi}

a. Tahu

Pengetahuan informan tentang program Rehabilitasi sesuai dengan apa yang di nyatakan oleh informan kunci tentang ilmu yang didapat informan selama menjalani program Rehabilitasi, dan informan utama juga mampu menerapkan ilmu yang didapat setelah menjalani program Rehabilitasi. Dari kutipan diatas juga didukung oleh (Notoadmodjo, 2012) yang mengatakan bahawa, Tahu dapat dartikan sebagai mengingat suatu materi yang telah dipelajari dari sebelumnya, termasuk didalam pengetahuan ini adalah mengingat kembali terhadap suatu yang spesifik dari seluruh bahan yang dipelajari atau rangsangan yang telah diterima.

b. Memahami

Berdasarkan hasil penelitian secara wawancara yang dilakukan oleh peneliti kepada informan dapat diketahui bahwa klien dapat atau bisa memahami apapun materi yang diberikan oleh konselor selama mengikuti program rehabilitasi, hal ini diungkapkan oleh informan pertama yaitu sebagai klien, klien mengungkapkan dirinya memahami materi yang di berikan oleh konselor contohnya Anger Management yaitu pengelolaan rasa marah atau emosi, klien mengatakan dari materi itu dirinya bisa tau bagaimana cara mengontrol rasa marahnya selain Anger Management dirinya juga banyak memahami materi-materi lain, diantaranya adalah Comunication Effectiv dan sebagainya. Hal yang sama juga diungkapkan oleh informan kedua yaitu sebagai klien, informan mengungkapkan banyak materi yang dirinya pahami diantaranya adalah materi tentang bahaya narkoba dan juga materi-materi lain sama seperti klien lain yang diajarkan untuk mengendalikan emosi, keinginan dan hal 
lain agar bisa mengarah kepada hal-hal yang possitif.

\section{Mengetahui sikap klien setelah} mengikuti program rehabilitasi

a. Menerima

Informan dapat merubah sikap dirinya dari kepribadian yang penuh emosi menjadi kepribadian yang bisa mengontrol setiap emosi-emosi yang keluar dari dirinya. Hal ini dirasakan oleh klien disaat dirinya berbicara dengan orang tuanya, klien mengatakan bahwa dirinya sudah bisa bertutur kata sopan dan menghormati orang tua, klien juga mengatakan bahwa dampak dari dirinya bisa menerima atau meresapi materi pembelajaran pada saat mengikuti program rehabilitasi $\mathrm{BNN}$.

b. Merespon

Klien dapat merasakan dan mampu terbuka terhadap apapun hal yang diberikan kepada klien mulai dari pertanyaan ataupun segala contoh-contoh yang diberika konselor pada saat klien mengikuti rehabilitasi. Klien mengatakan bahwa dirinya diajak bercerita untuk meluapkan perasaan ataupun gejala-gejala yang dirasakan sehingga membuat dirinya untuk menggunakan Narkoba lagi, dari proses bercerita ataupun meluapkan semua hal-hal yang dirasakan klien, klien pun mendapat solusi-solusi dari konselor agar bisa terjauh dari perasaan relapse ( Ingin menggunakan Narkoba) kembali. Selain bercerita kepada konselor, klien pun mengatakan bahwa dirinya juga sering mengajak sesame klien yang menjalani proses rehabilitasi untuk saling bercerita tentang pengalaman ataupun segala keluh kesah pada saat menggunakan Narkoba tersebut.

Informan kunci yaitu konselor yang ada di BNN provinsi, informan mengatakan bahwa mereka sering sekali melakukan interaksi kepada para klien agar bisa membiasakan diri untuk terbuka dalam menguapkan isi perasaan, agar para konselor pun bisa paham dan tau bagaimana cara dan langkah-langkah mereka untuk membantu para klien tersebut dalam menghadapi masalah terutama masalah dari penggunaan Narkoba. Dan hasil dari interaksi tersebut, para konselor mengungkapkan bahwa para klien bisa merespon apapun kegiatan interaksi yang diberikan oleh para konselor, sehingga para konselor bisa paham dengan apapun perasaan atau masalah yang sedang dihadapi para klien, sehingga tahapantahapan penyembuhan bisa berjalan sesuai dengan perencanaan yang ada di program rehabilitasi.

3. Mengetahui Perubahan Yang Dirasakan Klien Setelah Mengikuti Program Rehabilitasi

Hasil wawancara kepada 2 Informan utama, 1 Informan kunci, dan 2 informan pendukung, yang mempunyai tujuan untuk mengetahui perubahan- 
perubahan apa saja yang dirasakan klien pada saat mengikuti program rehabilitasi.

a. Evaluasi

Informan diketahui bahwa program rehabilitasi yang dilakukan di BNN Provinsi Kalimantan Timur mendapat hal possitf terutama dari perubahan-perubahan yang ditunjukan oleh para klien yang mengikuti program rehabilitasi tersebut, hal ini diungkapkan langsung oleh informan kunci yaitu konselor dari BNN Provinsi yang mengatakan bahwa banyak perubahan yang terjadi pada klien, informan kunci mengungkapkan bahwa perubahan yang terjadi pada diri klien yaitu dari sikap, sikap klien yang pada awalnya adalah orang yang sangat keras kepala dan sulit untuk mendengar apapun masukan dari orang lain, kini klien tersebut pun sudah berubah derastis karna mengikuti program tersebut. Informan pendukung mengatakan perubahan terjadi pada diri klien tidak lain dikarnakan dari diri klien itu sendiri yang mau mengalahkan Ego dirinya dan mau berdamai dengan sekitar, klien pun terlihat mencoba untuk mau mendengarkan segala nasehat dari orang-orang didekatnya terutama para tim konselor yang membantu dalam program rehabilitasi tersebut.

b. Adopsi

Sudah bisanya klien mengontrol emosi diungkapkan juga itu sebagai pencapaian terbaik di dirinya karna yang klien sangat ketahui bahwa dirinya adalah orang yang sangat keras kepala, dan klien juga sudah bisa mencari jalan keluar untuk dirinya menyelesaikan masalah, yaitu dengan cara mengungkapkan atau menceritakan masalah tersbut kepada orang tuanya, agar ketika dirinya mempunyai masalah dirinya tidak lagi tergoda untuk menggunakan lagi barang haram yang membuat dirinya tenang sesaat.

Penerapan merupakan sebuah tindakan yang dilakukan baik secara individu maupun kelompok dengan maksud untuk mencapai tujuan

yang telah dirumuskan. Adapun unsur-unsur penerapan meliputi :

1. Adanya program yang dilaksanakan

2. Adanya kelompok target, yaitu masyarakat yang menjadi sasaran dan diharapkan akan menerima manfaat dari program tersebut.

3. Adanya pelaksanaan, baik organisasi atau perorangan yang bertanggung jawab dalam pengelolaan, pelaksanaan maupun pengawasan dari proses penerapan tersebut

Informan merasa bersyukur terhadap perubahan-perubahan yang terjadi pada anaknya,informan pun berharap anaknya tidak lagi menggunakan barang haram tersebut dan kembali menjadi pribadi yang negative seperti sebelum dia mengikuti program rehabilitasi di $\mathrm{BNN}$ Provinsi Kalimantan timur tersebut. 
4. Peran Dukungan Sosial klien Dalam Menjalani Program Rehabilitasi

a. Dukungan Emosional

Untuk mengetahui dukungan emosional apa yang diberikan oleh informan kepada klien agar klien menjadi semangat dan percaya diri untuk lepas dari gangguan penggunaan Narkoba. Dari hasil wawancara tersebut dapat diketahui bahwa informan kunci pastinya memberi dukungan yang sangat penuh kepada klien agar mau percaya diri dalam mengikuti program rehabilitasi tersebut. Informan mengatakan dukungan sangatlah dibutuhkan klien karna klien pasti merasa dirinya ketika sudah menggunakan barang yang terlarang tersebut pastinya klien merasa dirinya adalah orang yang sangat mengecewakan dan tidak pantas untuk hidup lagi, maka dari itu dukung emosional sangat dibutuhkan dalam hal tersebut agar klien bisa menrasa percaya diri dan merasa dirinya bisa sembuh dari godaan barang tersebut. Konselor mengatakan bahwa selain rehabilitasi kepada klien yang menjadi pengguna, pihak konselor juga mengadakan program khususnya kepada keluarga klien yang biasa disebut dengan Family support grub yaitu bertujuan untuk mengajarkan bagaimana cara membangun kepedulian yang sangat erat ketika keluarga memberikan segala perhatiannya kepada klien tersebut agar klien bisa merasakan adanya ketenangan dalam keseharian, dikarenakan dukungan dengan cara peduli kepada apa saja yang menjadi keluhan oleh klien itu akan memberikan semangat tersendiri kepada klien, apalagi dukungandukungan tersebut selalu ada disaat klien mengikuti program ataupun ketika klien sudah selesai dari program tersebut.

b. Dukungan Informasi

Menurut penelitian wawancara kepada orang tua klien yaitu informan pendukung dalam penelitian ini mengungkap hal yang sesuai dengan apa yang diungkapkan oleh informan pendukung. Informan mengungkapkan bahwa mereka selalu memberikan saran dan selalu menanyakan hal-hal apa saja yang membuat klien mempunyai keinginan menggunakan narkoba kembali. Hal ini sesuai dengan arahan dari tim konselor BNN provinsi yang memberikan keputusan penuh kapada orang tua klien memberikan saran dan mengontrol apa saja kegiatan dari klien yang bisa membuat keinginan ingin menggunakan narkoba tersbut, dan sudah seharusnya sebagai orang tua harus memberikan saran agar klien bisa terlepas dari pikiran ingin menggunakan barang tersebut. Hal tersebut juga didukung oleh Sarafino (2011), dukungan informasi, keluarga berfungsi sebagai sebuah kolektor dan disseminator (penyebar) informasi tentang dunia . Dukungan informasi terjadi dan diberikan oleh keluarga dalam bentuk nasehat, saran dan diskusi tentang 
bagaimana cara mengatasi atau memecahkan masalah yang ada. Dan menurut (Apollo \& Cahyadi, 2012), dukungan informasi yang dimaksud adalah berupa nasehat, saran,arahan,dan informasi.informasi yang dimaksud mungkin sportif jika ia relevan dengan penilaian diri, seperti pemberian nasehat tentang apa yang harus dilakukan,dan individu yang memberikan dukungan juga dapat merekomendasikan tindakan dan rencana spesifik untuk membantu seseorang dalam copingnya dengan berhasil.

\section{KESIMPULAN}

1. Dari hasil yang diperoleh, menunjukan bahwa pengetahuan klien sudah sangatlah baik dan klien juga mampu menjelaskan/mengingat ilmu apa saja yang didapat saat menjalani program rehabilitasi.

2. Klien dapat merubah sikapnya dari kepribadian yang buruk dan penuh emosi dan juga menerima setiap arahan yang diberikan dan mampu menjalani setiap langkah-langkah yang ada pada saat mengikuti program rehabilitasi, dan klien pun mampu berinteraksi dengan baik kepada sesama klien maupun terhadap konselor dan mampu terbuka untuk menceritakan masalah pada klien saat mengikuti program rehabilitasi.
3. Klien menunjukan perubahan yang signifikan terhadap dirinya hal itu dibuktikan dari pihak konselor maupun keluarga klien yang ikut merasakan perubahan yang dialami oleh klien setelah menjalani proses rehabilitasi, dan klien juga mampu menerapkan atau mempraktekan hal-hal yang diberikan setelah mengikuti program Rehabilitasi.

4. Dukungan yang diberikan orang tua maupun konselor sangatlah berpengaruh terhadap penyembuhan klien hal itu dibuktikan dari perhatian yang selalu diberikan oleh pihak keluarga serta saran dan arahan maupun nasehat untuk klien agar lebih percaya diri didalam proses penyembuhannya dan pihak konselor pun sangat mensupport pihak keluarga dalam pemberian dukungan yang dilakukan sehingga pihak BNN Provinsi Kalimantan timur membuat program family support grup yg diperuntukan khusus keluarga dimana didalam pemberian dukungan sangat dibutuhkan oleh klien saat menjalani proses rehabilitasi.

\section{REFERENSI}

Ali, 2010.Konsep dukungan keluarga. Jakarta: salemba medika

Anas,Sudijono2012.PengantarEvaluasiPendid ikanJakarta:RajaGrafindoPersada http://digilib.unila.ac.id/3082/15/BA B\%20II.pdf

Apollo \& Andi Cahyadi. 2012. Konflik Peran Ganda Perempuan Menikah yang 
Bekerja Ditinjau dari Dukungan Sosial Keluarga dan Penyesuaian Diri. Madiun : Program Studi Psikologi, Fakultas Psikologi, Universitas Katolik Widya Mandala Madiun.

A.Wawan \& Dewi M. 2011. Teori dan Pengukuran Pengetahuan, Sikap, dan Perilaku Manusi.Cetakan II. Yogyakarta : Nuha Medika

Badan Narkotika Nasional.2007. Mengenal Penyalahgunaan Narkoba (Buku 2A). Jakarta : BNN Republik Indonesia.

Badan Narkotika Nasional Republik Indonesia.2009. Pencegahan Penyalahgunaan Narkoba. Jakarta.

BNN. 2012. Mahasiswa \& Bahaya Narkotika.Jakarta: Badan Narkotika Nasional Republik Indonesia.

Badan Nakotika Nasional , 2015 Press Release Akhir Tahun http://bnn.go.id/_multimedia/docume nt/20151223/press_release_akhir_ta hun_2015 20151223 003357.pdf, diakses 10 Desember 2017.

Badan Nakotika Nasional , 2016 Press Release Akhir Tahun. http://bnn.go.id/_multimedia/docume nt/20160810/press_release_akhir_ta hun_2016 20160810_20_08.pdf, diakses 10 Desember 2017

Badan Nakotika Nasional , 2017 Press Release Akhir Tahun. http://bnn.go.id/ multimedia. Diakses 10 Desember 2017

Badan Nakotika Nasional , 2018 Press Release Akhir Tahun. http://bnn.go.id/ multimedia. 21 Agustus 2019

Badan Nakotika Nasional , 201) Press Release Akhir Tahun. http://bnn.go.id/ multimedia/2017/10/13/09285110/pr ess release akhir tahun 2019130056 10476.pdf, 21 Agustus 2019

BNN. BADAN NARKOTIKA NASIONAL REPUBLIK INDONESIA (2018), misi Sejarah BNN. 5 OKTOBER
2018.

bnn.go.id/read/peage/8005/sejarahbnn\# diakses 20 Oktober, 2018.

Borba, Michele.2008. Membangun Kecerdasan Moral: Tujuh Kebajikan Utama untuk Membentuk Anak Bermoral Tinggi. (Alih bahasa: Lina Jusuf).Jakarta: Gramedia Pustaka Utama

Depkes RI. 2009. Sistem kesehatan nasional. Erdiana, Yuyun. 2015. Dukungan Keluarga Dalam kunjungan Lansia Di posyandulansiaDiDesaKaranglolorK ecamatanSukerejoKabupatenPonoro go. KTI. Tidak diterbitkan ponorogo : Program studi D III Keperawatan Falkultas Ilmu Kesehatan Universitas Muhammadiyah Ponorogo

Gani, Hafied Ali. 2015. Rehabilitasi Sebagai Upaya Depenalisasi Bagi Pecandu Narkotika,Universitas Brawijaya Malang.

G, Balogun, Anthony. 2014. Dispotional Factors, Perceived Social Support and Happiness Among Prison Inmates in Nigeria : A new look"( Faktor Disposisi, Dukungan Sosial dan Kebahagiaan Yang Dirasakan di Antara Narapidana Penjara di Nigeria). The Journal of Happiness \& Well-Being.

Gono, JN Suryanto 2007. Narkoba: Bahaya Penyalahgunaan dan Pencegahannya.

Hidayat, A.A.. 2014. Metode penelitian keperawatan dan teknis analisis data.Jakarta : Salemba Medika.

Husni, H.S. 2010. Evaluasi Pengendalian Sistem Informasi Penjualan. Jakarta http://library.binus.ac.id/eColls/eTh esisdoc/Bab2/2012-1-00343ka\%202.pdf.

Iruloh, B. R., \& Ukaegbu, H. M. 2017. Social Support, Coping Strategies and Academic Adjustment of First Year University Undergraduates in Rivers State, Nigeria. British Journal of Psychology Research. 
Imroatin. \& Ranu, M. E. 2014. Stres kerja, motivasi kerja, dengan dukungan sosial sebagai variabel moderator. Jurnal Ilmu Manajemen.

Isnawati, D. \& Suhariadi, F. 2013. Hubungan antara dukungan sosial dengan penyesuaian diri masa persiapan pensiun pada karyawan PT Pupuk Kaltim. Jurnal Psikologi Industri dan Organisasi.

Jamal Ma'mur Asmani. 2011. Buku Panduan Internalisasi Pendidikan Karakte di Sekolah. Yogyakarta: Diva Press.

Jazuli. 2007. Upaya menjaga diri dari bahaya narkoba. Semarang: PT Bengawan ilmu.

junker, S. 2011. Linking Health Communication with Social Support. Mattson's

Health as Communication Nexus

LA King . 2012. Psikologi Umum: Sebuah

Pandangan Apresiatif Jakarta: Salemba Humanika.

Lase, WN. 2011.Analisis Faktor-Faktoryang Mempengaruhi Kualitas Hidup Pasien.

Notoatmodjo S. 2012. Promosi Kesehatan dan Perilaku Kesehatan. Jakarta: PT Rineka Cipta.

Ratnasari, Z. 2017. Dukungan sosial dan work life balance pada karyawati dengan sistem shift. Skripsi. Yogyakarta: Fakultas Psikologi Universitas Islam Indonesia.

Reber, A. S; Reber, E. S. 2010. Kamus Psikologi (terjemahan). Yogyakarta: Pustaka Pelajar.

Ricardo, Paul, 2010. Upaya Penanggulangan Penyalahgunaan Narkoba Oleh Kepolisian (Studi Kasus Satuan Narkoba Polres Metro Bekasi), Vol.6 No III.
Riyadi, Muhammad Manfalutfhi. 2011. Implementasi Pelaksanaan Rehabilitasi Bagi Pecandu Narkotika Dan Korban Penyalahgunaan Narkotika.

Sasongko, Sri Sundari. 2009. Konsep Dan Teori Gender. Jakarta: BKKBN.

Sarafino, Edward P., Timothy W. Smith. 2011. Health Psychology Biopsychosocial Interactions Seventh edition. United States of America

Sunarno.2007. Narkoba, Bahaya dan Upaya Pencegahannya. Semarang: PT Bangawan ilmu.

Smith, N. 2012. Employees Reveal How Stress Affects Their Jobs.

Sugiyono. 2011. Metode Penelitian Kuantitatif, Kualitatif dan $R \& D$. Bandung: Afabeta

Suseno \& Sugiyanto. 2010. Pengaruh dukungan sosial dan kepemimpinan transformasional terhadap komitmen organisasi dengan mediator motivasi kerja. Jurnal Psikologi

Suwandi Joko, Drs. 2011. Penelitian Tindakan Kelas Classroom Action Research. Surakarta.

Tatas Nur. 2013. Implementasi Rehabilitasi Pecandu Narkotika Dalam Undang-Undang Republik Indonesia Nomor. 35 Tahun 2009 Tentang Narkotika Sebagai Upaya Non Penal Badan Narkotika Nasional, Universitas Brawijaya, Malang.

Undang-Undang No 35 tahun 2009 Pasal 1 tentang Narkotika.

Wawan dan Dewi, 2010, Teori dan Pengukuran Pengetahuan, Sikap dan Perilaku Manusia, Yogyakarta : Nuha Medika. 